\title{
Synergistic Supramolecular Effect on the Electro-Oxidation of Biological Relevant Molecules: A Novel Sensor for Simultaneous Determination of Epinephrine and Uric Acid in Human Urine Using MWCNT and a Copper(II) Complex
}

\author{
Bruno R. L. Ferraz, ${ }^{\oplus a, b}$ Fernando R. F. Leite, ${ }^{b}$ Eliziana S. Gomes, ${ }^{b}$ Marcus L. Sousa, ${ }^{c}$ \\ Eduardo G. R. de Arruda, ${ }^{c}$ Juliano A. Bonacin, ${ }^{\circ}{ }^{c}$ Andréa R. Malagutti ${ }^{b}$ and \\ André L. B. Formiga ${ }^{\oplus * c}$ \\ ${ }^{a}$ Departamento de Biologia, Universidade Federal do Espírito Santo (UFES), \\ 29500-000 Alegre-ES, Brazil \\ ${ }^{b}$ Departamento de Farmácia, Universidade Federal dos Vales do Jequitinhonha e Mucuri (UFVJM), \\ Rodovia MGT 367, km 583, 5000, Alto da Jacuba, 39100-000 Diamantina-MG, Brazil \\ 'Instituto de Química, Universidade Estadual de Campinas (UNICAMP), \\ P.O. Box 6154, 13084-971 Campinas-SP, Brazil
}

\begin{abstract}
In this paper a novel supramolecular strategy to improve the efficiency of a voltammetric sensor to determine two biologically relevant molecules (epinephrine (EP) and uric acid (UA)) is presented. The strategy is based on the use of a glassy carbon electrode modified with a copper(II) complex $\left(\left[\mathrm{Cu}\left(\mathrm{H}_{2}\right.\right.\right.$ dimpy $\left.\left.) \mathrm{Cl}\right] \mathrm{PF}_{6}\right)$ adsorbed on multi-walled carbon nanotubes (MWCNTs). The $\left[\mathrm{Cu}\left(\mathrm{H}_{2} \mathrm{dimpy}\right)\right.$ $\mathrm{Cl}] \mathrm{PF}_{6} / \mathrm{MWCNT}$ composite-supported electrode was characterized by electrochemical impedance spectroscopy, scanning electron microscopy (SEM) and energy dispersive spectroscopy (EDS). The electrocatalytic oxidation of EP and UA using the sensor was investigated by cyclic voltammetry and square wave voltammetry. Under optimized conditions, voltammetric peak currents showed a linear response for the EP and UA concentrations in the ranges 0.5-159.2 and 0.2-58.5 $\mu \mathrm{mol} \mathrm{L}^{-1}$, whereas the limits of detection were 0.2 and $0.05 \mu \mathrm{mol} \mathrm{L}^{-1}$, respectively. The sensor was successfully applied in the selective and simultaneous determination of EP and UA in human urine samples. Thus, our results showed that the supramolecular strategy was successful to build an efficient sensor for simultaneous detection of these molecules in biological samples.
\end{abstract}

Keywords: epinephrine, uric acid, simultaneous determination, electrochemical sensor, copper complex, inorganic supramolecular chemistry

\section{Introduction}

The bottom-up strategy is based on the concept of building blocks and is a central idea of Supramolecular Chemistry. This strategy has proved extremely versatile for the construction of molecular nanomaterials. Supermolecules, as polymolecular entities, can self-organize to form a variety of structures such as films, layers, membranes, micelles, etc. ${ }^{1,2}$ When these integrated chemical systems have the ability to perform specific functions like recognition, transport or transformation, they are known as supramolecular devices. ${ }^{3}$ From the point of view of

*e-mail: formiga@unicamp.br

Dedicated to Prof Henrique Eisi Toma on the occasion of his $70^{\text {th }}$ birthday. electrochemical sensors development, usually the analyte is detected by a redox reaction and the sensitivity is a function of the performance of a electrocatalyst. Supramolecular chemistry approach can be strategically used in several ways to improve efficiency, for example by improving the catalytic activity itself (by providing an alternative lower energy reaction path) or by improving the analyte loadings in the sensor phase. Our group has shown some examples of this supramolecular strategy in both homogeneous ${ }^{4}$ and heterogeneous reactions. ${ }^{5}$

In a series of previous works, ${ }^{6-8}$ we have shown that a polymer bearing coordinating groups can be used to immobilize a highly charged coordination compound directly on the surface of multi-walled carbon nanotube (MWCNT). The effect is the enhancement of the catalytic 
performance for the detection of cysteine by accelerating the charge transfer reaction. In that case, without the supramolecular structure, there is no net reaction between the electron transfer mediator and the analyte.

Herein, this work reports a different supramolecular strategy to improve the efficiency of an electrochemical sensor. For the first time we present the electrochemical preparation, characterization and application of a glassy carbon electrode (GCE) modified with MWCNTs and a copper(II) complex for simultaneous quantification of epinephrine (EP) and uric acid (UA). The chosen copper(II) complex is key for a proof of concept because it combines the potential for van der Waals interactions with CNT, hydrogen bonds with the target molecules and the ability for proton-coupled electron transfers, all in the same structure. The strong Jahn-Teller effect on the $3 \mathrm{~d}^{9} \mathrm{Cu}^{\mathrm{II}}$ ion induces a planar coordination mode for the complex, as we have shown recently, ${ }^{9}$ making room for face-to-face $\pi-\pi *$ van der Waals interactions with the walls of MWCNTs. This would increase the loading of the complex onto the electrode surface and improve the electronic interaction between mediators. Moreover, we have recently shown ${ }^{10,11}$ that the $\mathrm{H}_{2}$ dimpy (2,6-di(1H-imidazol-2-yl)pyridine) ligand shows a rich proton-coupled electrochemical behavior at positive potentials. On top of that, the metal ion decreases the oxidation potential of $\mathrm{H}_{2}$ dimpy as a consequence of its Lewis acidity and a further combination of its planar structure and the ability to act as proton or hydrogen-bond donor could culminate in an interesting supramolecular effect. It is worth mentioning that hydrogen bonding plays an important role in the conception of electrochemical sensors for specific targets. Molecules or supramolecular structures attached to electrodes and capable of forming hydrogen bonding can promote stronger interactions between the electroactive layer and the analyte and, as a consequence, the electron transfer process can be faster. ${ }^{12,13}$

In our previous works, ${ }^{7,8}$ we have also shown that MWCNT can greatly improve the efficiency of electrochemical sensors. MWCNTs are carbon nanostructured materials ${ }^{14,15}$ that have been used to modify electrodes because of their unique electronic, chemical and mechanical properties, such as high electrical conductivity, high surface area, chemical stability and high electrocatalytic effect. Furthermore, several works have described the use of MWCNTs treated with metal complexes for the modification of electrodes. These combined materials provide excellent catalytic properties to the electrode, resulting in high selectivity and sensitivity for effective electrochemical analysis. ${ }^{7,8,16-18}$ As a proof of concept for our supramolecular strategy, we have selected as targets two biologically relevant molecules that present a rich proton coupled electrochemistry and are difficult to analyze simultaneously.

Epinephrine (4-[(1R)-1-hydroxy-2-(methylamino) ethyl]benzene-1,2-diol, EP) is an important catecholamine neurotransmitter in the mammalian nervous system. It also plays a vital role in the functionality of the renal, endocrine, central and cardiovascular systems. Its presence in the body affects blood pressure and heart rate, lipolysis, immune system and glycogen metabolism. ${ }^{19}$ Oscillating EP levels may be attributed to the etiopathology of some diseases, for instance low EP concentrations are usually found in patients with Parkinson's disease. ${ }^{20}$ Uric acid (7,9-dihydro$1 H$-purine-2,6,8(3H)-trione, UA) is the principal product of purine metabolism. ${ }^{21}$ Normal levels of UA are from 0.24 to $0.52 \mathrm{mmol} \mathrm{L}^{-1}$ in serum and 1.4 to $4.4 \mathrm{mmol} \mathrm{L}-1$ in urine. ${ }^{22}$ Abnormal UA levels result from altered purine metabolism, which is directly related to numerous illnesses, for example gout, hyperuricemia, severe hepatitis, LeschNyhan syndrome. ${ }^{23}$ In addition, unusual UA concentrations may be associated with renal impairment. ${ }^{24}$ In this sense, monitoring the UA concentration in the blood and urine is highly important to facilitate the diagnosis of the abovementioned diseases.

Due to the biological relevance of EP and UA, it has been necessary to develop sensors for their quantification that could also exhibit low cost, portability, high sensitivity, low limits of detection (LOD), selectivity and fast response. Electroanalysis has several desirable features for use in routine diagnosis; however, EP and UA usually coexist in human biological fluids and are oxidized at very similar potentials, resulting in an overlap of their electroanalytical signals with poor sensitivity for bare solid electrodes, and thus preventing their simultaneous determination. In addition, EP/UA oxidation products can be adsorbed or electropolymerized onto the electrode surface, promoting its partial passivation and negatively affecting its detectability and reusability. ${ }^{25}$ In this context, several electroanalytical methods based on modified electrodes have been recently described for the simultaneous determination of EP and UA. ${ }^{26-30}$ These methods have been employed to quantify EP and UA in pharmaceutical and biological fluids with satisfactory linear range, LOD and limit of quantification (LOQ). Our work shows that the supramolecular strategy can be satisfactory to build an efficient sensor for simultaneous detection of these molecules.

\section{Experimental}

Details of the chemicals, reagents, solutions and apparatus are provided in the Supplementary Information (SI) section. 


\section{Synthesis of copper(II) complex}

The $\mathrm{H}_{2}$ dimpy was synthesized using the procedure described by Voss et al. ${ }^{31}$ The copper(II) complex $\left(\left[\mathrm{Cu}\left(\mathrm{H}_{2}\right.\right.\right.$ dimpy $\left.\left.) \mathrm{Cl}\right] \mathrm{PF}_{6}\right)$ has been synthesized and fully characterized by Arruda et al., ${ }^{9}$ whose procedure consists in mixing 1 equivalent of $\mathrm{H}_{2}$ dimpy and $\mathrm{CuCl}_{2}$ in a 1:1 water to methanol mixture. This synthesis is an adaptation of the methodology reported by Stupka et al..$^{32}$

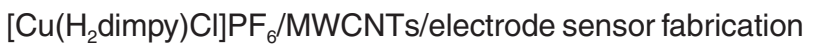

The GCE surface was first polished with an alumina slurry on a polishing pad, which was followed by successive sonication in ethanol to remove the adsorbed alumina particles. The electrode was then rinsed with double distilled water and allowed to dry at room temperature. Further, $10 \mu \mathrm{L}$ of MWCNT dispersions $(0.50,1.0,1.5$, $2.0,2.5$ or $3.0 \mathrm{mg} \mathrm{mL}^{-1}$ ) prepared by sonication, and $\left[\mathrm{Cu}\left(\mathrm{H}_{2}\right.\right.$ dimpy $\left.) \mathrm{Cl}\right] \mathrm{PF}_{6}(15.0,30.0,45.0$ or $60.0 \mu \mathrm{g} \mathrm{mL}-1)$ in $1.0 \mathrm{~mL}$ of methanol, were placed directly onto the GCE electrode surface. The electrode was dried at room temperature to form the $\left[\mathrm{Cu}\left(\mathrm{H}_{2}\right.\right.$ dimpy $\left.) \mathrm{Cl}\right] \mathrm{PF}_{6} / \mathrm{MWCNT}$ composite on the GCE electrode surface. The modified electrode was thoroughly rinsed with deionized water and placed into the electrochemical cell.

Millimolar concentrations of $\left[\mathrm{Cu}\left(\mathrm{H}_{2} \mathrm{dimpy}\right) \mathrm{Cl}\right] \mathrm{PF}_{6}$ in water were not achievable due to the very low solubility of the complex. Carbon paste electrodes were then prepared with graphite and the complex $(20 \% \mathrm{~m} / \mathrm{m})$ using Nujol. A hollow electrode with $2 \mathrm{~mm}$ diameter and a copper wire contact was used in these electrochemical experiments.

\section{Electrochemical measurements}

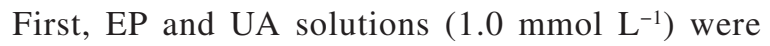
prepared by dissolving the required amount of the stock solutions in $0.10 \mathrm{~mol} \mathrm{~L}^{-1}$ phosphate buffered saline (PBS, $\mathrm{pH}=7.0$ ). A volume of $10.0 \mathrm{~mL}$ of each solution was placed in the electrochemical cell and the cyclic voltammogram was registered. The cyclic voltammograms were recorded at $50 \mathrm{mV} \mathrm{s}^{-1}$ in the potential range from -0.1 to $+0.8 \mathrm{~V}$ using four different electrodes surface (bare GCE; $\left[\mathrm{Cu}\left(\mathrm{H}_{2}\right.\right.$ dimpy)Cl] $\mathrm{PF}_{6} / \mathrm{GCE}$; MWCNTs/GCE and $\left[\mathrm{Cu}\left(\mathrm{H}_{2} \mathrm{dimpy}\right) \mathrm{Cl} \mathrm{PF}_{6} / \mathrm{MWCNTs} / \mathrm{GCE}\right)$. The optimization of the amount of $\left[\mathrm{Cu}\left(\mathrm{H}_{2} \mathrm{dimpy}\right) \mathrm{Cl}\right] \mathrm{PF}_{6}$ and MWCNT for electrode preparation was performed by cyclic voltammetry $(\mathrm{CV})$. Afterwards, cyclic voltammograms were recorded in the sweep range of $10-100 \mathrm{mV} \mathrm{s}^{-1}$ with initial sweep to positive potentials by using the optimized $\left[\mathrm{Cu}\left(\mathrm{H}_{2}\right.\right.$ dimpy $\left.) \mathrm{Cl}\right] \mathrm{PF}_{6} / \mathrm{MWCNTs} / \mathrm{GCE}$. The effect of $\mathrm{pH}$ on the simultaneous determination of EP and UA was also investigated by $\mathrm{CV}$ at $50 \mathrm{mV} \mathrm{s}^{-1}$ in $0.10 \mathrm{~mol} \mathrm{~L}^{-1}$ PBS over the $\mathrm{pH}$ range from 6.0 to 8.5 . The analytical method was developed using square wave voltammetry (SWV) and its parameters (potential pulse amplitude, potential step increment and frequency) were optimized to assess the optimum experimental performance for the simultaneous determination of EP and UA with the $\left[\mathrm{Cu}\left(\mathrm{H}_{2} \mathrm{dimpy}\right) \mathrm{Cl}\right] \mathrm{PF}_{6} / \mathrm{MWCNTs} / \mathrm{GCE}$. To optimize the parameters, the potential pulse amplitude was varied from 10 to $100 \mathrm{mV}$, maintaining the potential step increment and frequency fixed at $1 \mathrm{mV}$ and $50 \mathrm{~s}^{-1}$, respectively. The potential step increment was studied in the interval 1-10 mV maintaining the potential pulse amplitude and frequency fixed at $70 \mathrm{mV}$ and $60 \mathrm{~s}^{-1}$, respectively. Finally, the frequency was varied over the range $10-100 \mathrm{~s}^{-1}$, with the potential pulse amplitude and potential step increment fixed at 70 and $3 \mathrm{mV}$, respectively. The optimized square-wave voltammetric parameters were as follows: potential pulse amplitude of $70 \mathrm{mV}$, potential step increment of $3 \mathrm{mV}$, and a frequency of $60 \mathrm{~s}^{-1}$.

\section{Job's method}

The interaction between $\left[\mathrm{Cu}\left(\mathrm{H}_{2} \text { dimpy }\right) \mathrm{Cl}\right]^{+}$and EP (and UA) in water solution was investigated through Job's method using $0.1 \mathrm{mmol} \mathrm{L}^{-1}$ solutions prepared with PBS (pH 7.0). Several solutions were prepared in which the molar fraction of each component was varied, keeping the total molar amount constant. The resulting UV-Vis spectra were recorded and analyzed accordingly (Figures S1 and S2, SI section).

\section{Analysis on real samples and tests of interference}

The proposed $\left[\mathrm{Cu}\left(\mathrm{H}_{2}\right.\right.$ dimpy $\left.) \mathrm{Cl}\right] \mathrm{PF}_{6} / \mathrm{MWCNT}$ composite electrode was used to investigate real samples by direct analysis of EP and UA in human urine samples. The urine samples were provided by healthy, non-smoking volunteers aged 20 to 30 years. The collection of urine samples was carried out according to a standard procedure which establishes that the first morning urine sample must be collected, due to its concentration, ensuring the detection of chemical substances and elements present in the urine. The collection procedure was performed after cleaning the urogenital region and the first stream of urine was neglected. The medium stream urine was collected up to half the capacity of a bottle of inert material, clean, dry, leak-proof and disposable, with a capacity of $80 \mathrm{~mL}$. After collection, samples were kept under refrigeration at a temperature of $4{ }^{\circ} \mathrm{C}$ until the moment of analysis. To perform the analysis, 
first, the human urine samples were diluted 25 times with $0.10 \mathrm{~mol} \mathrm{~L}^{-1}$ phosphate buffer $(\mathrm{pH} 7.0)$. Then, the urine samples were spiked with 90.0 and $3.5 \mu \mathrm{mol} \mathrm{L}{ }^{-1}$ of EP and UA, respectively.

The selectivity of the proposed method was evaluated by interference studies with the substances ascorbic acid, serotonin, glucose, acetaminophen, L-dopa and citric acid. Some of these substances are found in human urine at different concentrations. Thus, to assess the effect of interference on the electroanalytical response of the EP, an EP solution with a concentration of $90.0 \mu \mathrm{mol} \mathrm{L} \mathrm{L}^{-1}$ and interference concentration of $50.0 \mathrm{mmol} \mathrm{L}^{-1}$ were used maintaining an analyte:interference ratio of approximately 1:550. In addition, to evaluate the effect of the interference on the electroanalytical response of the UA, an UA solution

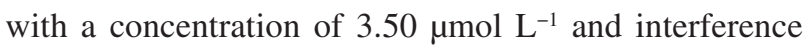
concentration of $50.0 \mathrm{mmol} \mathrm{L}^{-1}$ were used maintaining an analyte:interference ratio of approximately 1:14000. In order to carry out this study, initially the peak current signals of the EP and UA were recorded at a concentration of 90 and $3.50 \mu \mathrm{mol} \mathrm{L}^{-1}$, respectively. The intensities of the peak current signals obtained for the EP and UA without the interference compounds were considered as $100 \%$ response. After that, the peak current signals of the EP and UA were obtained in the presence of $50.0 \mathrm{mmol} \mathrm{L}^{-1}$ of each interference and it was verified the possible changes in the peak current signals of the analytes in the presence of interference compounds. Thus, the relative response was calculated that allowed assessing the percentage of interference.

\section{Electrochemical impedance spectroscopy}

Electrochemical impedance spectroscopy (EIS) has been widely used to characterize interfacial properties of surface-modified electrodes. A typical impedance spectrum (presented as a Nyquist plot) includes a semicircle portion at higher frequencies corresponding to electron-transfer limited processes, and a linear part at lower frequencies that describes diffusion-limit processes. The semicircle diameter of the impedance spectrum is equal to the chargetransfer kinetics of the probe redox at the electrode surface. The measurements were performed at formal potential of the $1.0 \mathrm{mmol} \mathrm{L}{ }^{-1}\left[\mathrm{Fe}\left(\mathrm{CN}_{6}\right)\right]^{3-} /\left[\mathrm{Fe}\left(\mathrm{CN}_{6}\right)\right]^{4-}$ redox couple (1:1) plus $0.10 \mathrm{~mol} \mathrm{~L}^{-1} \mathrm{KCl}$ solution. The NOVA software ${ }^{33}$ based on the simplex optimization and nonlinear leastsquare-fit was used to fit the EIS data. The frequency range was $0.1-10^{5} \mathrm{~Hz}$. The charge-transfer resistance $\left(\mathrm{R}_{\mathrm{ct}}\right)$ values were obtained by non-linear regression on the semicircle portion of the Nyquist plots $\left(\mathrm{Z}_{\mathrm{im}} v s . \mathrm{Z}_{\mathrm{re}}\right){ }^{34}$

\section{Theoretical calculations}

A model for CNT walls and their interaction with the complex, and between complex and EP and UA, was constructed by using a strategy of combining the universal force field (UFF), ${ }^{35}$ the PM6 and the PM6-D3H4 hamiltonians, the latter incorporating corrections for hydrogen bonding and dispersion based on Grimme's D3 method. ${ }^{36}$ All semiempirical calculations were performed as implemented in MOPAC2016. ${ }^{37}$ A detailed description of the methods and strategy is available at SI section.

\section{Results and Discussion}

\section{Composite characterization}

The characterization of the unmodified MWCNTs and $\left[\mathrm{Cu}\left(\mathrm{H}_{2}\right.\right.$ dimpy $\left.) \mathrm{Cl}\right] \mathrm{PF}_{6} / \mathrm{MWCNT}$ composite was performed by scanning electron microscopy (SEM) (Figures 1a and 1b) and energy dispersive spectroscopy (EDS) (Figures 1c and 1d). The SEM micrograph in Figure 1a shows a good level of distribution of the samples on the GCE surface. Apparently, when Figures $1 \mathrm{a}$ and $1 \mathrm{~b}$ are compared, the addition of $\left[\mathrm{Cu}\left(\mathrm{H}_{2}\right.\right.$ dimpy $\left.) \mathrm{Cl}\right] \mathrm{PF}_{6}$ to MWCNT does not change the morphology of the surface. As expected, the EDS image of the MWCNT (Figure 1c) shows only the presence of carbon but the $\left[\mathrm{Cu}\left(\mathrm{H}_{2}\right.\right.$ dimpy $\left.) \mathrm{Cl}\right] \mathrm{PF}_{6} / \mathrm{MWCNT}$ EDS (Figure 1d) reveals the additional presence of $\mathrm{Cu}, \mathrm{Cl}$, $\mathrm{O}$ and $\mathrm{N}$ related to the atom types present in the complex confirming the formation of the composite between the complex and the MWCNTs on the surface of the electrode.

\section{Electrochemical impedance spectroscopy (EIS) analysis}

EIS is a powerful and emerging tool to study interfacial electron transfer properties and to identify the surface nature of modified electrodes. Figure 2 shows the real and imaginary parts of the impedance spectra displayed as Nyquist plots.

The impedance spectra were fitted by interpreting the electrochemical cell as a modified Randles circuit (inset in Figure 2), which includes the solution resistance $\left(\mathrm{R}_{\mathrm{s}}\right)$ in series with the constant phase element corresponding to the double-layer capacitance (DLC). The DLC is in parallel to the charge-transfer resistance $\left(\mathrm{R}_{\mathrm{ct}}\right)$, which in turn, is in series with the Warburg impedance (W). The Warburg impedance represents the diffusion of ferro/ ferricyanide from the electrolyte solution bulk towards the electrode surface. The semicircle of the Nyquist plot 

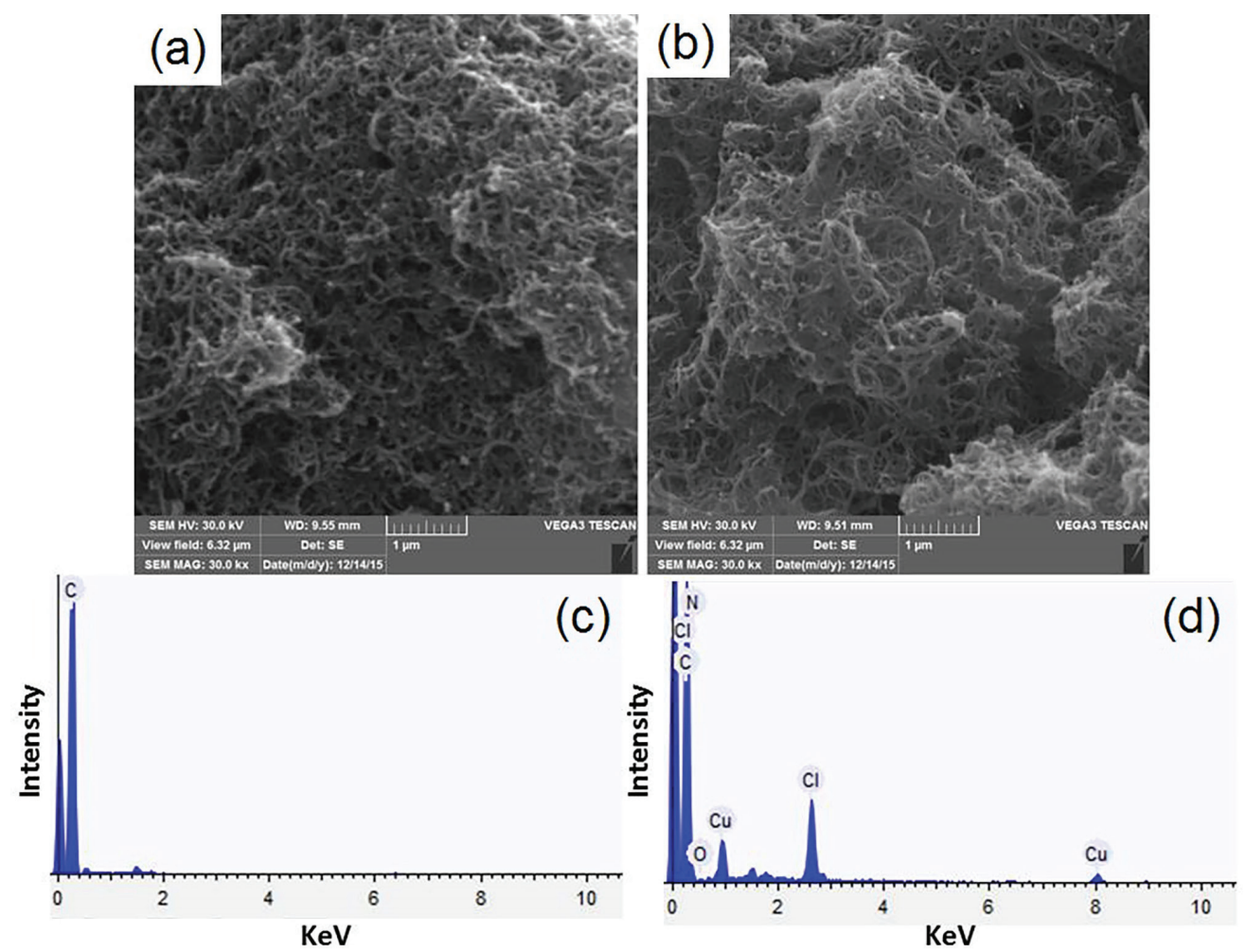

Figure 1. SEM and their corresponding EDS images of (a, c) unmodified MWCNT, and (b, d) $\left[\mathrm{Cu}\left(\mathrm{H}_{2} \mathrm{dimpy}\right) \mathrm{Cl}\right] \mathrm{PF}_{6} / \mathrm{MWCNT}$ composite.

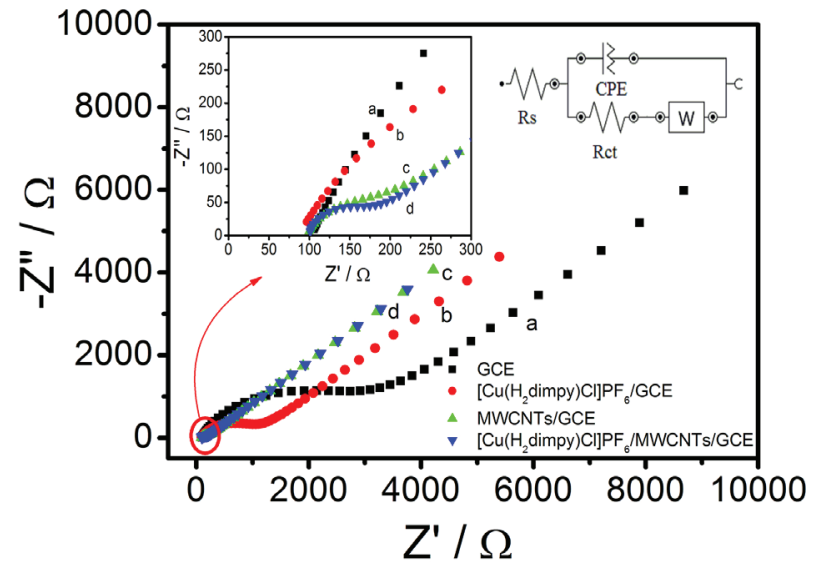

Figure 2. Nyquist plot of $1.0 \mathrm{mmol} \mathrm{L}^{-1}\left[\mathrm{Fe}\left(\mathrm{CN}_{6}\right)\right]^{3-} /\left[\mathrm{Fe}\left(\mathrm{CN}_{6}\right)\right]^{4-}$ solution in $0.10 \mathrm{~mol} \mathrm{~L}^{-1} \mathrm{KCl}$ for (a) $\mathrm{GCE}$; (b) $\left[\mathrm{Cu}\left(\mathrm{H}_{2} \mathrm{dimpy}\right) \mathrm{Cl}\right] \mathrm{PF}_{6} / \mathrm{GCE}$; (c) MWCNTs/GCE and (d) $\left[\mathrm{Cu}\left(\mathrm{H}_{2}\right.\right.$ dimpy)Cl] $\mathrm{PF}_{6} / \mathrm{MWCNTs} / \mathrm{GCE}$. Working electrode potential: $+0.2 \mathrm{~V}$. Inset: selected region in the Nyquist plot and standard Randles equivalent-model circuit applied for calculations. obtained at high frequency corresponds to the electrontransfer limited process, and its diameter is equal to $R_{c t}$. The $\mathrm{R}_{\mathrm{s}}, \mathrm{R}_{\mathrm{ct}}, \mathrm{W}$ and DLC values for the different electrodes are summarized in Table 1.

In the high frequency region, a large welldefined semi-circle was observed for the bare GCE $\left(\mathrm{R}_{\mathrm{ct}}=2880.0 \pm 140.7 \Omega\right)$, indicating a poor interfacial electron transfer. $R_{\mathrm{ct}}$ decreased to $996.0 \pm 45.7$ and to $102.0 \pm 1.7 \Omega$ for the $\left[\mathrm{Cu}\left(\mathrm{H}_{2}\right.\right.$ dimpy $\left.) \mathrm{Cl}\right] \mathrm{PF}_{6} / \mathrm{GCE}$ and MWCNTs/GCE, respectively, indicating that these modifications increased the electron transfer rate, the presence of CNTs showing the most pronounced effect, as expected. In addition, the smallest semi-circle was observed when the GCE surface was simultaneously modified with MWCNTs and $\left[\mathrm{Cu}\left(\mathrm{H}_{2}\right.\right.$ dimpy)Cl]PF , and the $\mathrm{R}_{\mathrm{ct}}$ value decreased to $69.2 \pm 0.7 \Omega$, proving that there is a synergistic effect on the electron transfer rate.

Table 1. Nyquist plot parameters obtained for different electrodes

\begin{tabular}{lcccc}
\hline Electrode & $\mathrm{R}_{\mathrm{s}} / \Omega$ & $\mathrm{R}_{\mathrm{ct}} / \Omega$ & $\mathrm{W} / \mu \mathrm{mho}$ & $\mathrm{DLC} / \mu \mathrm{F}$ \\
\hline Bare GCE & $102.0 \pm 1.4$ & $2880.0 \pm 140.7$ & $149.0 \pm 5.7$ & $3.60 \pm 0.5$ \\
$\mathrm{MWCNTs} / \mathrm{GCE}$ & $97.0 \pm 1.1$ & $102.0 \pm 1.7$ & $219.0 \pm 10.2$ & $2.90 \pm 0.3$ \\
{$\left[\mathrm{Cu}\left(\mathrm{H}_{2} \mathrm{dimpy}\right) \mathrm{Cl}\right] \mathrm{PF}_{6} / \mathrm{GCE}$} & $86.5 \pm 0.57$ & $996.0 \pm 45.7$ & $203.0 \pm 7.9$ & $2.60 \pm 0.2$ \\
{$\left[\mathrm{Cu}\left(\mathrm{H}_{2} \mathrm{dimpy}\right) \mathrm{Cl}\right] \mathrm{PF}_{6} / \mathrm{MWCNTs} / \mathrm{GCE}$} & $100.0 \pm 1.7$ & $69.2 \pm 0.7$ & $248.0 \pm 12.7$ & $0.31 \pm 0.07$ \\
\hline
\end{tabular}

$\mathrm{R}_{\mathrm{s}}$ : solution resistance; $\mathrm{R}_{\mathrm{ct}}$ : charge-transfer resistance; W: Warburg impedance; DLC: double-layer capacitance; GCE: glassy carbon electrode; MWCNT: multiwalled carbon nanotube. 
Interaction between $\mathrm{CNT}$ and $\left[\mathrm{Cu}\left(\mathrm{H}_{2} \text { dimpy }\right) \mathrm{Cl}\right]^{+}$

In order to explain the important changes in the $\mathrm{R}_{\mathrm{ct}}$ obtained by EIS we decided to build a theoretical model for the interaction between CNT and the complex. Due to the complexity of the problem, a simpler model was studied consisting of a truncated single-walled CNT (SWCNT). We employed the semiempirical PM6-D3H4 hamiltonian that incorporates corrections for hydrogen bonding and dispersion. After optimization the expected tubular geometry for SWCNT was obtained with $1.2 \mathrm{~nm}$ diameter and $2.0 \mathrm{~nm}$ length (Figure 3 ). The equilibrium geometry for the supramolecular interaction reveals that an offset stacked $\pi-\pi^{*}$ interaction is favorable in which the separation between the plane of the complex and the closest six-membered ring on the surface of the CNT is $3.3 \AA$, in the typical range for this kind of interactions. ${ }^{38}$ The potential energy surface (PES) (Figure 3) along the distance between these planes reveals that a typical Morse potential describes the interaction. The total energies obtained were fitted to an equation of the type $V(r)=D_{e}\left(1-e^{-\alpha\left(r-r_{e}\right)}\right)^{2}$ in which $V$ is the potential energy, $D_{e}$ represents the dissociation energy for the supramolecular pair, $r$ is the distance between the components and $r_{e}$ the equilibrium distance $(3.3 \AA)$. The constant a represents the width of the potential curve. From the fitting we can estimate the value for $D_{e}=20 \mathrm{kcal} \mathrm{mol}^{-1}$ which is also in very good agreement with what is expected for a $\pi$-stacked system. ${ }^{38}$ These results suggest that the same stacked $\pi-\pi^{*}$ (supramolecular) interaction could be found in $\left[\mathrm{Cu}\left(\mathrm{H}_{2}\right.\right.$ dimpy)Cl] $\mathrm{PF}_{6} / \mathrm{MWCNTs} / \mathrm{GCE}$ composites. Taking into consideration that our model is very simplistic in comparison with real samples we should take the $D_{e}$ value as a rough estimate for what is really happening in the composite samples. However, even if the exact energetics of the interaction cannot be calculated, one can anticipate that the decrease in $\mathrm{R}_{\mathrm{ct}}$ can be regarded as a result of the presence of this supramolecular structure acting synergistically as opposed to a simple additive effect of two hypothetical separate domains (MWCNT + complex) on the surface of the electrodes.

Electrochemical behaviors of EP and UA on bare GCE, [Cu( $\mathrm{H}_{2}$ dimpy)Cl]PF ${ }_{6} / \mathrm{GCE}, \mathrm{MWCNTs/GCE}$ and [Cu( $\mathrm{H}_{2}$ dimpy)Cl]PF 6 /MWCNTs/GCE

The electrochemical behavior of $1.0 \mathrm{mmol} \mathrm{\textrm {L } ^ { - 1 }} \mathrm{EP}$ and UA in $0.10 \mathrm{~mol} \mathrm{~L}^{-1} \mathrm{PBS}(\mathrm{pH}=7.0)$ for the different electrodes were scrutinized by $\mathrm{CV}$ at $50 \mathrm{mV} \mathrm{s}^{-1}$ over the potential range from -0.1 to $+0.8 \mathrm{~V}$. For the bare GCE, the EP presented an irreversible oxidation peak at $0.42 \mathrm{~V}$, while UA showed an irreversible oxidation peak at $0.38 \mathrm{~V}$ (Figure 4a). Under these conditions, the simultaneous determination of EP and UA becomes impossible due to the overlap of their oxidation peaks.

For the GCE modified only with $\left[\mathrm{Cu}\left(\mathrm{H}_{2}\right.\right.$ dimpy $\left.) \mathrm{Cl}\right]$ $\mathrm{PF}_{6}$ (Figure $4 \mathrm{~b}$ ), the peak current of EP decreased, while the peak current of UA increased slightly. The use of $\left[\mathrm{Cu}\left(\mathrm{H}_{2}\right.\right.$ dimpy)Cl] $\mathrm{PF}_{6} / \mathrm{GCE}$ resulted in a more difficult oxidation of the analytes, shifting the peak potential towards more positive values $(0.44$ and $0.54 \mathrm{~V}$ for EP and UA, respectively). The oxidation of the complex is not observed in the CVs. To confirm the absence, we prepared carbon paste electrodes (with high loadings of the complex) and confirmed that in the working potential range (up to $1.0 \mathrm{~V}$ ) the oxidation is not observed at $\mathrm{pH}=$ 7 (Figures S3 and S4, SI section). For the GCE modified only with MWCNTs (Figure 4c) an electrocatalytic effect was observed in the determination of EP and UA, that is, the peak potentials were shifted to lower potentials (+0.077 and $+0.27 \mathrm{~V}$ for EP and UA, respectively). Furthermore, a reduction peak for UA was observed at $+0.23 \mathrm{~V}$. The electrochemical response of $\left[\mathrm{Cu}\left(\mathrm{H}_{2} \mathrm{dimpy}\right)\right.$
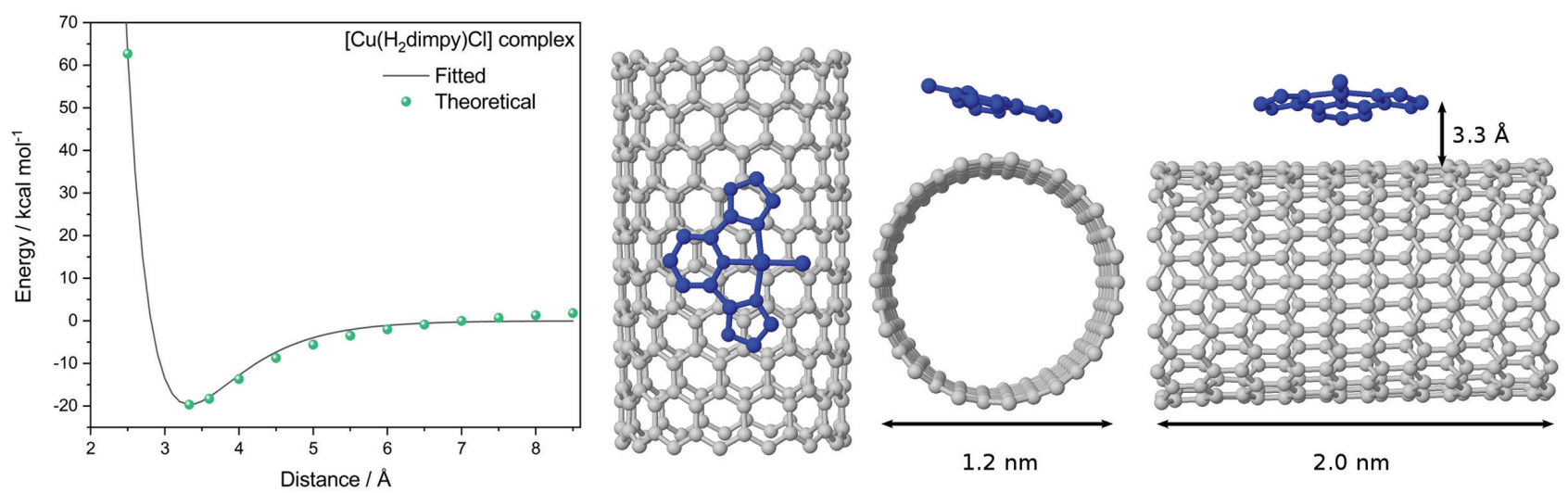

Figure 3. Potential energy surface (left) for the interaction between the model SWCNT and $\left[\mathrm{Cu}\left(\mathrm{H}_{2} \mathrm{dimpy}\right) \mathrm{Cl}\right]^{+}$: calculated using the PM6-D3H4 hamiltonian (circles); fitted to a Morse potential (line). On the right, three views of the optimized supramolecular structure in which the complex is shown in contrast with the CNT. Hydrogen atoms were omitted. 

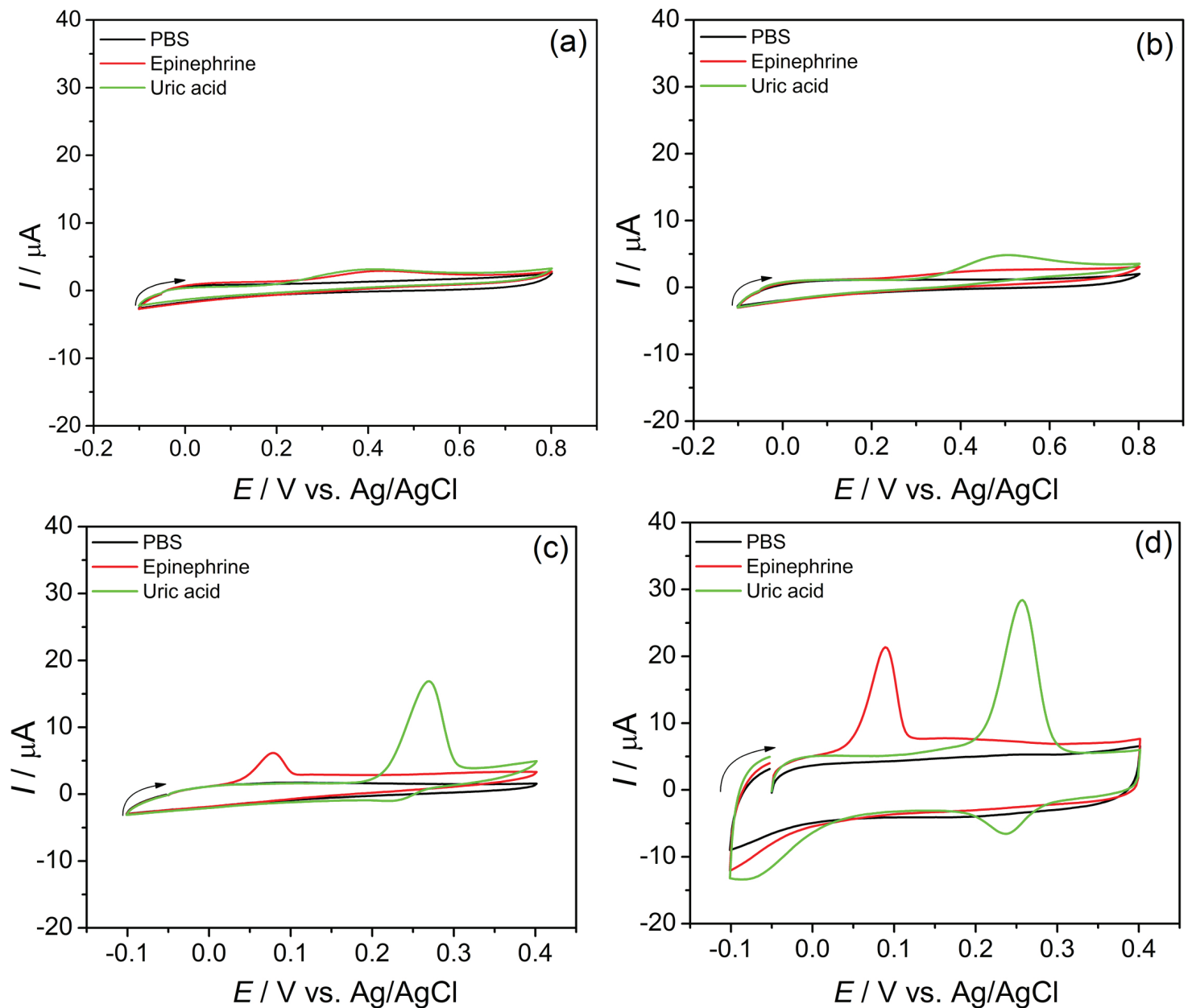

Figure 4. Cyclic voltammograms of $1.0 \mathrm{mmol} \mathrm{L}^{-1} \mathrm{UA}$ (green line), $1.0 \mathrm{mmol} \mathrm{L} \mathrm{m}^{-1} \mathrm{EP}$ (red line) and phosphate buffer solution (PBS) (black line) recorded with: (a) bare GCE; (b) $\left[\mathrm{Cu}\left(\mathrm{H}_{2} \mathrm{dimpy}\right) \mathrm{Cl}\right] \mathrm{PF}_{6} / \mathrm{GCE}$; (c) MWCNTs/GCE and (d) $\left[\mathrm{Cu}\left(\mathrm{H}_{2} \mathrm{dimpy}\right) \mathrm{Cl}\right] \mathrm{PF}_{6} / \mathrm{MWCNTs}_{\mathrm{GCE}} \mathrm{v}=50 \mathrm{mV} \mathrm{s}{ }^{-1}$; electrolyte: $0.10 \mathrm{~mol} \mathrm{~L}{ }^{-1}$ PBS $(\mathrm{pH}=7.0)$.

$\mathrm{Cl}_{\mathrm{PF}_{6}} / \mathrm{MWCNTs}_{\mathrm{GCE}}$ (Figure 4d) is very distinct showing the peak current increase for both molecules, more than $100 \%$ for EP and ca. 50\% for UA in comparison with the MWCNTs/GCE electrode. The increase is also present for the reduction peak of UA that is now observed at a higher potential. We have also performed an optimization of the amount of complex and MWCNT (SI section). The use of $30.0 \mu \mathrm{g} \mathrm{mL} \mathrm{m}^{-1}$ of $\left[\mathrm{Cu}\left(\mathrm{H}_{2}\right.\right.$ dimpy $\left.) \mathrm{Cl}\right] \mathrm{PF}_{6}$ and $2.0 \mathrm{mg} \mathrm{mL}^{-1}$ of MWCNT led to a modified GCE with the best repeatability and stability.

There is a remarkable difference between the oxidation peaks of these analytes $(193 \mathrm{mV})$ thus justifying the use of $\left[\mathrm{Cu}\left(\mathrm{H}_{2} \mathrm{dimpy}\right) \mathrm{Cl}\right] \mathrm{PF}_{6} / \mathrm{MWCNTs} / \mathrm{GCE}$ to increase the resolution between their electrochemical signals.

\section{Effect of scan rates on cyclic voltammetry}

The effect of scan rate $(v)$ on the peak current was simultaneously investigated using $\mathrm{CV}$ in the range $10-100 \mathrm{mV} \mathrm{s}^{-1}$ (Figure S5, SI section). The anodic peak currents $\left(\mathrm{I}_{\mathrm{pa}}\right)$ of EP and UA for the mixed solution of $1.0 \mathrm{mmol} \mathrm{L}^{-1} \mathrm{EP}$ and $1.0 \mathrm{mmol} \mathrm{L}^{-1} \mathrm{UA}$ in $0.10 \mathrm{~mol} \mathrm{~L}^{-1}$ PBS $(\mathrm{pH}=7.0)$ increased with the increasing scan rate and they were linearly proportional to the scan rate within the studied range (Figure S5, inset a). This fact indicates that the electrode reactions of both analytes are controlled by adsorption on the $\left[\mathrm{Cu}\left(\mathrm{H}_{2} \mathrm{dimpy}\right) \mathrm{Cl}\right] \mathrm{PF}_{6} / \mathrm{MWCNT} / \mathrm{GCE}$ surface. Linear regression equations between $\mathrm{I}_{\mathrm{pa}}$ and $v$ for both analytes can be expressed by equations 1 and 2 :

EP: $\mathrm{I}_{\mathrm{pa}}(\mu \mathrm{A})=(0.098 \pm 0.001)+(0.54 \pm 0.02) v\left(\mathrm{mV} \mathrm{s}^{-1}\right)$, $\mathrm{R}^{2}=0.996$

UA: $I_{p a}(\mu A)=(-1.37 \pm 0.17)+(0.70 \pm 0.03) v\left(\mathrm{mV} \mathrm{s}^{-1}\right)$, $\mathrm{R}^{2}=0.994$

Also, the relationship between $\log \mathrm{I}_{\mathrm{pa}}$ and $\log \mathrm{v}$ (Figure S5, inset b) shows a linear correlation between $\log \mathrm{I}_{\mathrm{pa}}$ and $\log \mathrm{v}$ that can be expressed according to equations 3 and 4 : 
EP: $\log \mathrm{I}_{\mathrm{pa}}=(-6.12 \pm 0.05)+(0.96 \pm 0.03) \log \mathrm{v}$, $\mathrm{R}^{2}=0.996$

$\mathrm{UA}: \log \mathrm{I}_{\mathrm{pa}}=(-6.18 \pm 0.07)+(1.00 \pm 0.04) \log \mathrm{v}$, $\mathrm{R}^{2}=0.993$

The slopes of equations 3 and 4 are very close to the theoretical values reported in literature ${ }^{39,40}$ for adsorptioncontrolled processes. These results confirm that the ratelimiting step of the electrode reaction is an adsorption process and/or specific interactions occurring at the $\left[\mathrm{Cu}\left(\mathrm{H}_{2}\right.\right.$ dimpy) $\left.\mathrm{Cl}\right] \mathrm{PF}_{6} / \mathrm{MWCNT/GCE}$ surface.

\section{Effect of $\mathrm{pH}$ on the simultaneous determination of EP and UA}

The $\mathrm{pH}$ effect on the real-time determination of EP and UA was investigated by $\mathrm{CV}$ at $50 \mathrm{mV} \mathrm{s}^{-1}$ in $0.10 \mathrm{~mol} \mathrm{~L}^{-1}$ PBS over the supporting electrolyte $\mathrm{pH}$ ranging from 6.0 to 8.5. Figure 5 shows that the peak potential and peak current of EP and UA were influenced by the $\mathrm{pH}$, suggesting the involvement of protons in the oxidation processes.

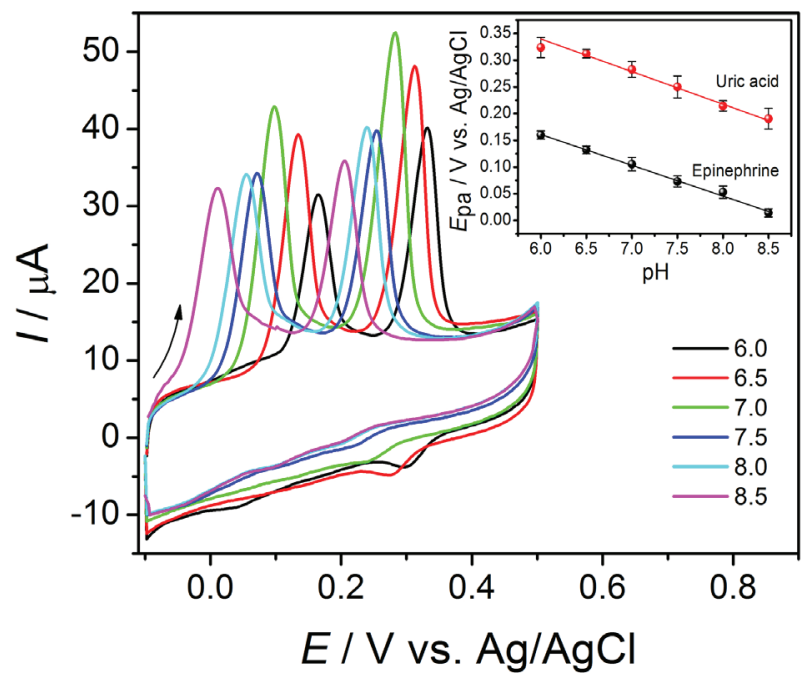

Figure 5. Cyclic voltammograms of $1.0 \mathrm{mmol} \mathrm{L}^{-1} \mathrm{EP}$ and $1.0 \mathrm{mmol} \mathrm{L} \mathrm{L}^{-1} \mathrm{UA}$ in $0.10 \mathrm{~mol} \mathrm{~L}^{-1} \mathrm{PBS}$ in different $\mathrm{pH}$ obtained with $\left[\mathrm{Cu}\left(\mathrm{H}_{2} \mathrm{dimpy}\right) \mathrm{Cl}\right] \mathrm{PF}_{6} / \mathrm{MWCNTs} / \mathrm{GCE} ; \mathrm{v}=50 \mathrm{mV} \mathrm{s}^{-1}$. Inset: anodic peaks potential $\left(\mathrm{E}_{\mathrm{pa}}\right)$ vs. $\mathrm{pH}$ plot.

The peak currents of EP and UA increased with the increasing solution $\mathrm{pH}$ up to 7.0 and then the current decreased with the further increasing $\mathrm{pH}$. Therefore, the physiological $\mathrm{pH}$ (7.0) was chosen for further investigations. As expected for both analytes, the peak potential shifted towards more negative values with increasing $\mathrm{pH}$ and the relationship between anodic peak potential $\left(\mathrm{E}_{\mathrm{pa}}\right)$ and supporting electrolyte $\mathrm{pH}$ is shown as an inset in Figure 5. The linear relationship for EP and UA are given by the following equations:
$\mathrm{EP}: \mathrm{E}_{\mathrm{pa}}(\mathrm{V})=(0.52 \pm 0.02)-(0.060 \pm 0.003) \mathrm{pH}$, $\mathrm{R}^{2}=0.992$

$\mathrm{UA}: \mathrm{E}_{\mathrm{pa}}(\mathrm{V})=(0.64 \pm 0.02)-(0.050 \pm 0.001) \mathrm{pH}$, $\mathrm{R}^{2}=0.994$

The slopes were estimated as -60 and $-50 \mathrm{mV} \mathrm{\textrm {pH } ^ { - 1 }}$ for EP and UA, respectively. Negative slopes indicated that deprotonation is involved in the oxidation process, which is facilitated at high $\mathrm{pH}$ values. ${ }^{30}$ Based on these results, it can be concluded that two electrons and two protons are involved in the electrode process of EP and UA. ${ }^{26-30}$

\section{Hydrogen bonding of $\left[\mathrm{Cu}\left(\mathrm{H}_{2} \text { dimpy }\right) \mathrm{Cl}\right]^{+}$with EP and UA}

The result of a synergistic effect between $\left[\mathrm{Cu}\left(\mathrm{H}_{2}\right.\right.$ dimpy $\left.) \mathrm{Cl}\right] \mathrm{PF}_{6}$ and MWCNTs as surface modifiers helps explain the enhancement of the electrode sensitivity. Results presented in previous sections suggest that the $\left[\mathrm{Cu}\left(\mathrm{H}_{2}\right.\right.$ dimpy $\left.) \mathrm{Cl}\right] \mathrm{PF}_{6} / \mathrm{MWCNTs} / \mathrm{GCE}$ is able to accelerate the electron transfer in the oxidation of EP and UA that involves the adsorption of the analytes on the surface of the electrode, according to the electrochemical studies.

To suggest a possible mechanism for this synergistic effect we investigated spectrophotometrically the interaction between the complex and the analytes in solution. The association between the species in solution was confirmed by the shift in the UV-Vis spectrum and the application of Job's method giving a 1:1 stoichiometry (Figures S1 and S2, SI section).

According to the literature, ${ }^{41}$ at $\mathrm{pH}=7 \mathrm{EP}$ is in its totally protonated state since its first $\mathrm{p} K_{\mathrm{a} 1}=8.0$, meaning that it has a positive charge under our experimental conditions. On the other hand, UA with a $\mathrm{p} K_{\mathrm{a} 1}=5.4^{42}$ is deprotonated bearing a negative charge. We expect the complex to be completely protonated since $\mathrm{p} K_{\mathrm{a} 1}>8$, based on similar complexes $^{32}$ and the results obtained form the free ligand ${ }^{10,11}$ resulting in a positive charge in solution as confirmed in our previous study. ${ }^{9}$ The comparison of $\mathrm{p} K_{\mathrm{a}}$ values is important because it shows that even when the two components are positively charged (in the case of EP) the interaction is observed experimentally, suggesting a strong interaction through hydrogen bonding.

Taking this scenario into account, we have studied theoretically the interaction between the complex and the molecules in their protonation states at $\mathrm{pH}=7$. For comparison purposes, we used the same methodology as employed for the calculation with SWCNT presented before. The results are summarized in Figure 6 showing that the PES obtained in both cases confirm the bonding of the molecules to the complex. The equilibrium geometries 
(Figure 6) reveal hydrogen bonds between one NH group of the complex and oxygen atoms of both analytes with $\mathrm{H}$... O distances ranging from $2.12 \AA$ for EP to $2.39 \AA$ for UA. The fitting of Morse potentials was used to estimate the interaction energy giving $9 \mathrm{kcal} \mathrm{mol}^{-1}$ for UA and $7 \mathrm{kcal} \mathrm{mol}^{-1}$ for EP. As discussed before, even if these numbers have to be regarded as rough estimates they clearly show that the formation of pairs between the species is possible and it is worth mentioning that the interaction is attractive no matter the charge of the analyte since the pair is neutral in the case of UA and doubly charged in the case of EP (see the sketches in Figure 6).

The previous results reinforce the proposed model that the composite acts in a synergistic way, MWCNT providing both a very good conductor medium and a platform for the $\pi$-stacking of the complex. The latter acts as a H-bond donor to keep the analytes close to the surface. Single-crystal X-ray diffraction studies combined with density functional theory on a series of similar molecules confirm that hydrogen bonds are the most
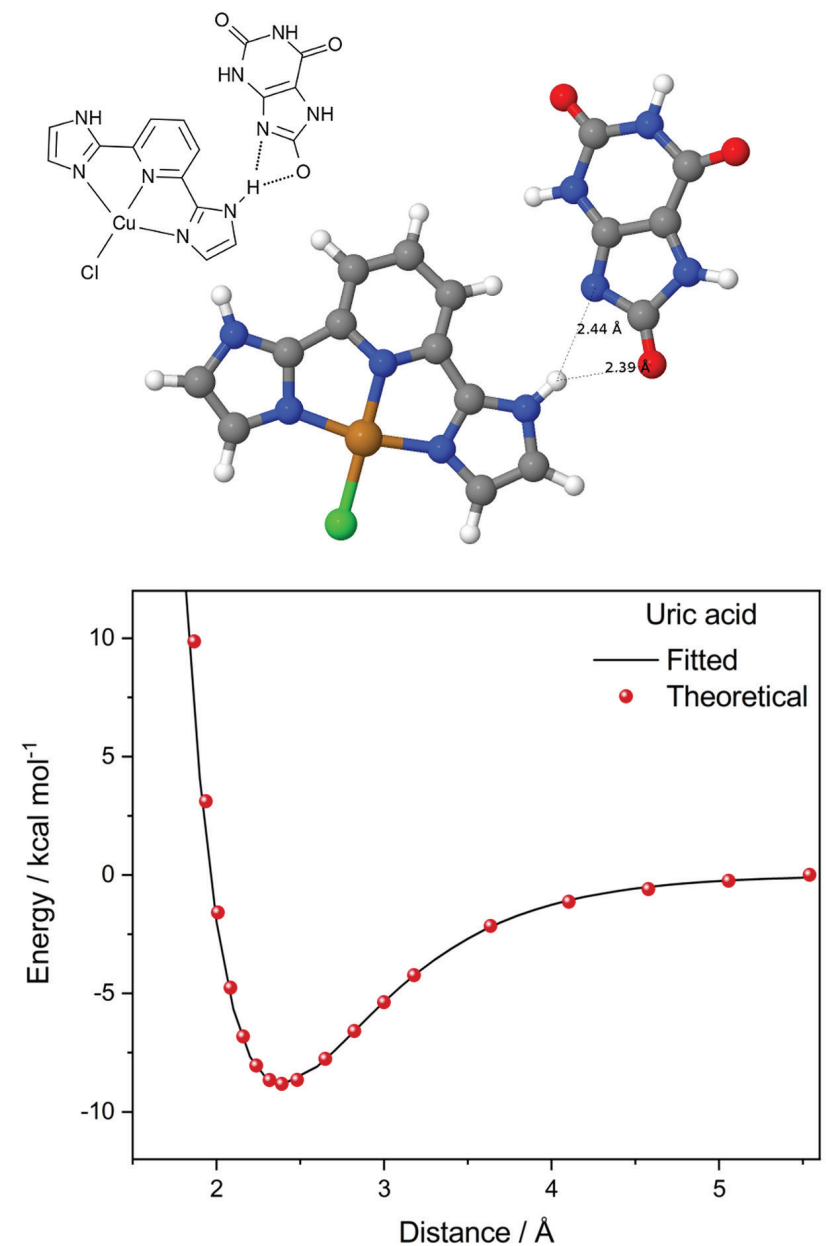

important supramolecular interactions in this class of imidazole-derived molecules. ${ }^{10,11}$ These combined effects probably play an important role in accelerating the first electron transfer step. However, the overall reaction is a two-electron process and to further investigate if after the first transfer the H-bond pair would be stable, we have studied the PES for the oxidized species. In this case, we have performed the vertical ionization of the analytes, assuming that after the first oxidation another proton is released by the structure. This is supported by the acidity increase upon oxidation, a phenomenon highly confirmed in the literature. ${ }^{10,11,42}$ The theoretical results (Figure S6, SI section) confirm that after the first oxidation the stability of both pairs increase, reinforcing the hypothesis that the synergistic effect is highly efficient in providing a faster mechanism for the proton coupled two-electron oxidation of both analytes.

The immobilization of the composite on the GCE surface promotes a heterogeneous electrocatalytic oxidation of EP and UA, facilitating electron transfer reactions.
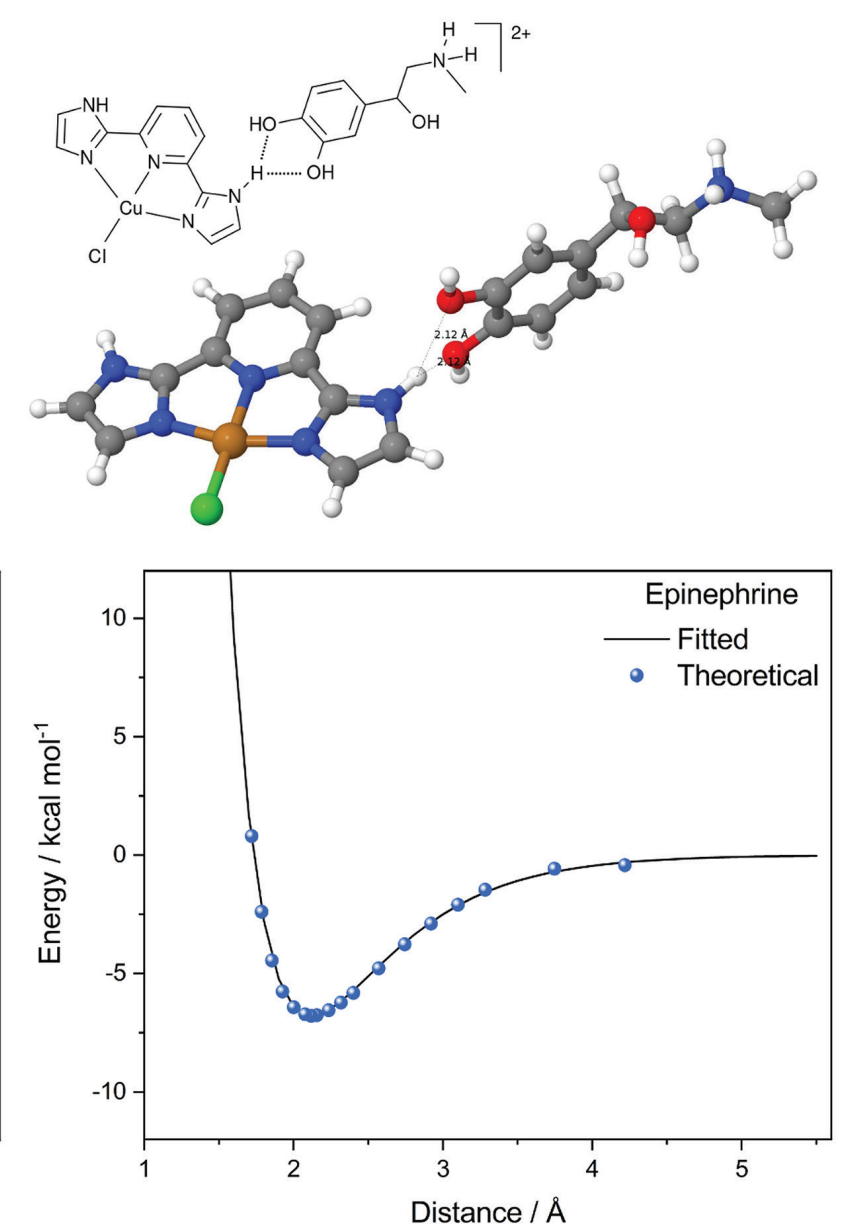

Figure 6. Potential energy surfaces (bottom) obtained for the interaction through hydrogen bonding between $\left[\mathrm{Cu}\left(\mathrm{H}_{2} \mathrm{dimpy}\right) \mathrm{Cl}\right]^{+}$and the anions of uric acid and epinephrine: calculated using the PM6-D3H4 hamiltonian (circles); fitted to a Morse potential (line). The corresponding equilibrium geometries are shown at the top together with a sketch of the structures, representing hydrogen bonds as dotted lines. The overall charge is zero for the UA pair and two for EP. 
The high activity of the proposed electrode sensor on the oxidation of EP and UA is due to the low charge transfer resistance of the $\left[\mathrm{Cu}\left(\mathrm{H}_{2}\right.\right.$ dimpy $\left.) \mathrm{Cl}\right] \mathrm{PF}_{6} / \mathrm{MWCNTs}$ composite, as well as to the high dispersion and fixation of the copper(II) complex throughout the MWCNTs.

\section{Effect of concentration of EP and UA by square-wave voltammetry}

Square wave voltammetry (SWV) presents higher sensitivity, better signal resolution and lower limit of detection than the CV technique. The square wave voltammetric parameters such as pulse amplitude (a), frequency (f) and step potential $\left(\Delta \mathrm{E}_{\mathrm{s}}\right)$ were optimized. Figure 7 shows the SWV for different concentrations of $\mathrm{EP}$ and UA in $0.10 \mathrm{~mol} \mathrm{~L}^{-1} \mathrm{PBS}(\mathrm{pH}=7.0)$ with applied potentials of $0.0-0.5 \mathrm{~V}$, under optimized conditions $\left(\mathrm{a}=70 \mathrm{mV}, \mathrm{f}=60 \mathrm{~s}^{-1}\right.$ and $\left.\Delta \mathrm{E}_{\mathrm{s}}=3 \mathrm{mV}\right)$.

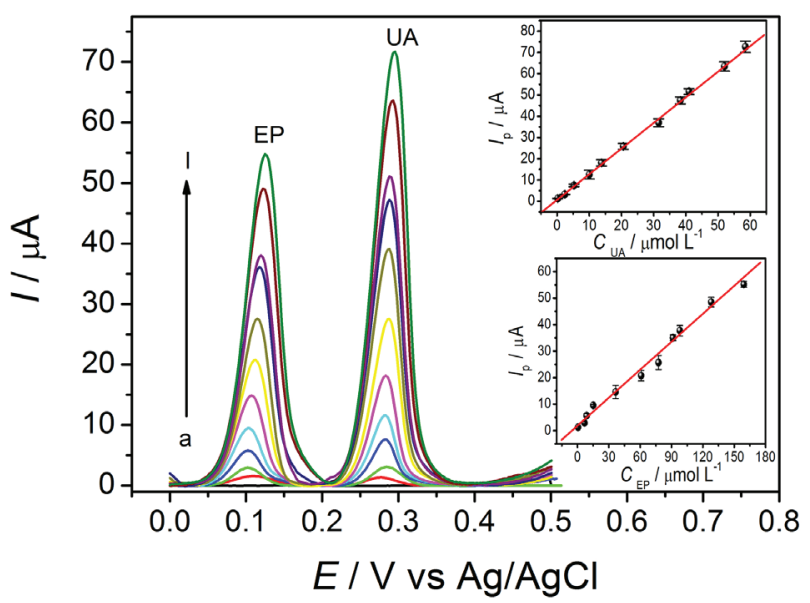

Figure 7. Square wave voltammograms of mixed solutions of EP and UA. EP concentrations (from a to l): (a) 0.00 ; (b) 0.53 ; (c) 6.76 ; (d) 8.80 ; (e) 15.14 ; (f) 36.50 ; (g) 61.67 ; (h) 77.50 ; (i) 91.48 ; (j) 98.68 ; (k) 128.40 and (l) $159.21 \mu \mathrm{mol} \mathrm{L}-1$. UA concentrations (from a to l): (a) 0.00 ; (b) 0.20 ; (c) 2.39 ; (d) 5.25 ; (e) 10.00 ; (f) 13.84 ; (g) 20.58 ; (h) 31.55 ; (i) 38.28 ; (j) 41.52 ; (k) 52.67 and (l) $58.51 \mu \mathrm{mol} \mathrm{L}^{-1}$. Optimized SWV conditions: $\mathrm{a}=70 \mathrm{mV}, \mathrm{f}=60 \mathrm{~s}^{-1}$ and $\Delta \mathrm{E}_{\mathrm{s}}=3.0 \mathrm{mV}$ in $0.10 \mathrm{~mol} \mathrm{~L}^{-1} \mathrm{PBS}(\mathrm{pH}=7.0)$ for $\left[\mathrm{Cu}\left(\mathrm{H}_{2} \mathrm{dimpy}\right) \mathrm{Cl}\right] \mathrm{PF}_{6} / \mathrm{MWCNTs} / \mathrm{GCE}$. Inset: relationships between oxidation peak currents and analytes concentrations.

Under these optimized conditions, the EP and UA concentrations were varied over the ranges 0.53-159.21 and $0.20-58.51 \mu \mathrm{mol} \mathrm{L}-1$, respectively. The oxidation peak currents were linearly proportional to the concentrations of EP and UA in the studied ranges. The relationships between current and concentration (C) for electro-oxidation of EP and UA can be expressed according to the following equations:

EP: $\mathrm{I}_{\mathrm{p}}(\mu \mathrm{A})=(1.87 \pm 0.30)+(0.351 \pm 0.005) \mathrm{C}_{\mathrm{EP}}\left(\mu \mathrm{mol} \mathrm{L} \mathrm{L}^{-1}\right)$,

$\mathrm{R}^{2}=0.990$
UA: $I_{p}(\mu A)=(0.682 \pm 0.098)+(1.205 \pm 0.018) C_{U A}\left(\mu m o l L^{-1}\right)$, $\mathrm{R}^{2}=0.997$

The LOD and LOQ were calculated in accordance to $\operatorname{IUPAC}^{43}\left(\mathrm{LOD}=3 \mathrm{~s}_{\mathrm{B}} / \mathrm{S}\right.$ and $\mathrm{LOQ}=10 \mathrm{~s}_{\mathrm{B}} / \mathrm{S}$, in which $\mathrm{s}_{\mathrm{B}}$ is the standard deviation of the baseline noise and $\mathrm{S}$ is the slope of the analytical curve). The LOD values calculated were 0.2 and $0.05 \mu \mathrm{mol} \mathrm{L} \mathrm{L}^{-1}$ for EP and UA, respectively. The LOQ values calculated were 0.7 and $0.17 \mu \mathrm{mol} \mathrm{L}^{-1}$ for EP and $\mathrm{UA}$, respectively. The analytical parameters obtained in this work were compared to the electroanalytical methods described in the literature (Table 2).

As can be seen in the Table 2, in this work, the linear range was wide, the LOD was low as the values already reported for simultaneous analysis of EP and UA by electrochemical methods and a good resolution $(193 \mathrm{mV})$ between the oxidation peaks of EP and UA was obtained showing that the developed method is selective. Also, when compared with the other works presented in the Table 2 this resolution value is among the best resolution results reported. Beyond these features, this developed method is simpler and can be applied for routine analysis.

\section{Intra-day and inter-day repeatability}

The intra-day repeatability of the EP and UA peak currents for $91.48 \mu \mathrm{mol} \mathrm{L}^{-1} \mathrm{EP}$ and $38.28 \mu \mathrm{mol} \mathrm{L}^{-1}$ UA in $0.10 \mathrm{~mol} \mathrm{~L}^{-1} \mathrm{PBS}(\mathrm{pH}=7.0)$ was evaluated by fifteen successive measurements of the peak current in the same solution. The relative standard deviation (RSD) values obtained were $2.86 \%$ (bias $=3.45 \%$ ) and $4.28 \%$ (bias $=4.17 \%$ ) for EP and UA, respectively, suggesting an adequate intra-day repeatability. Yet the inter-day repeatability of the EP and UA peak current for $91.48 \mu \mathrm{mol} \mathrm{L}{ }^{-1} \mathrm{EP}$ and $38.28 \mu \mathrm{mol} \mathrm{L}-1 \mathrm{UA}$ in $0.10 \mathrm{~mol} \mathrm{~L}^{-1}$ PBS ( $\mathrm{pH}=7.0)$ was assessed by recording the peak current for similar fresh solutions over a period of 8 days. Good RSD values were obtained: $4.29 \%$ (bias $=5.05 \%$ ) and $4.91 \%$ (bias $=4.97 \%$ ) for EP and UA, respectively, showing an adequate inter-day repeatability.

\section{Study of interference and analysis of real samples}

The interference of ascorbic acid, serotonin, glucose, acetaminophen, L-dopa and citric acid was investigated by comparing the oxidation signals of $90.0 \mu \mathrm{mol} \mathrm{L} \mathrm{L}^{-1} \mathrm{EP}$ and $3.50 \mu \mathrm{mol} \mathrm{L}^{-1}$ UA obtained by SWV without and with addition of these foreign compounds at high concentration $\left(50.0 \mathrm{mmol} \mathrm{L}^{-1}\right)$ (Figure 8). It is observed that the response of the analytes (EP and UA) remains practically $100 \%$ unchanged. The results revealed that the foreign compounds 
Table 2. Comparison between the proposed method and recently reported electrochemical methods towards simultaneous determination of EP and UA

\begin{tabular}{|c|c|c|c|c|c|c|c|c|c|c|}
\hline \multirow{2}{*}{ Technique } & \multirow{2}{*}{ Electrode } & \multirow{2}{*}{$\mathrm{pH}$} & \multicolumn{2}{|c|}{ Potential peak / V } & \multicolumn{2}{|c|}{ Linear range / $\left(\mu \mathrm{mol} \mathrm{L}{ }^{-1}\right)$} & \multicolumn{2}{|c|}{$\left.\mathrm{LOD} /(\mu \mathrm{mol} \mathrm{L})^{-1}\right)$} & \multirow{2}{*}{ Sample } & \multirow{2}{*}{ Reference } \\
\hline & & & EP & UA & EP & UA & EP & UA & & \\
\hline LSV & NDG/PGE & 7.0 & 0.147 & 0.3016 & $0.01-10$ & $0.01-60$ & 0.003 & 0.003 & $\begin{array}{l}\text { human serum and } \\
\text { urine }\end{array}$ & 26 \\
\hline DPV & $\begin{array}{c}\text { AuNPs/TGA/CS-MWCNTs/ } \\
\text { GCE }\end{array}$ & 7.0 & 0.240 & 0.470 & $0.4-11.0$ & $46-194.0$ & 0.06 & 0.032 & $\begin{array}{l}\text { pharmaceutical } \\
\text { and human serum }\end{array}$ & 29 \\
\hline DPV & 4NTP/4MBA/GE & 5.5 & 0.150 & 0.450 & $0.1-2.0$ & $1.0-175$ & 0.037 & 0.5 & - & 28 \\
\hline $\mathrm{CV}$ & graphene/GCE & 3.0 & 0.484 & 0.650 & $0.20-100$ & $0.60-120$ & 0.001 & 0.080 & urine & 44 \\
\hline DPV & Ox-PAP/GCE & 7.4 & 0.100 & 0.25 & $0.4-8.0$ & $0.4-8.0$ & 0.006 & 0.18 & pharmaceuticals & 45 \\
\hline DPV & MDWCNTPE & 7.0 & 0.065 & 0.280 & $0.7-1200$ & $25-750$ & 0.216 & 8.8 & $\begin{array}{l}\text { pharmaceutical } \\
\text { and human serum }\end{array}$ & 46 \\
\hline DPV & $\begin{array}{c}\text { activated glassy carbon } \\
\text { electrode }\end{array}$ & 5.0 & 0.190 & 0.350 & $1.00-40.00$ & $1.00-55.00$ & 0.089 & 0.16 & human serum & 47 \\
\hline DPV & DPDSAM/GE & 8.0 & 0.170 & 0.390 & $0.7-500$ & $10-750$ & 0.51 & 9.0 & pharmaceuticals & 48 \\
\hline SWV & $\begin{array}{c}{\left[\mathrm{Cu}\left(\mathrm{H}_{2} \text { dimpy }\right) \mathrm{Cl}\right] \mathrm{PF}_{6} /} \\
\text { MWCNTs/GCE }\end{array}$ & 7.0 & 0.077 & 0.270 & $0.5-159.2$ & $0.2-58.5$ & 0.2 & 0.05 & human urine & this paper \\
\hline
\end{tabular}

LOD: limit of detection; EP: epinephrine; UA: uric acid; LSV: linear sweep voltammetry; NDG/PGE: modified pyrolytic graphite electrode with nanodiamond/graphite; DPV: differential pulse voltammetry; AuNPs/TGA/CS-MWCNTs/GCE: Au-nanoparticles on thioglycolic acid/chitosan-multi-walled carbon nanotubes/glassy carbon electrode; 4NTP/4MBA/GE: 4-nitrothiophenol/4-mercaptobenzoic acid binary on gold electrode; CV: cyclic voltammetry; Ox-PAP/GCE: over-oxidized poly(p-aminophenol)/glassy carbon electrode; MDWCNTPE: 2,2-[1,2-ethanediylbis(nitriloethylidyne)]-bis-hydroquinone double-wall carbon nanotube paste electrode; DPDSAM/GE: gold electrode modified by 2-(2,3-dihydroxy phenyl)-1,3-dithiane self-assembled monolayer; SWV: square wave voltammetry.

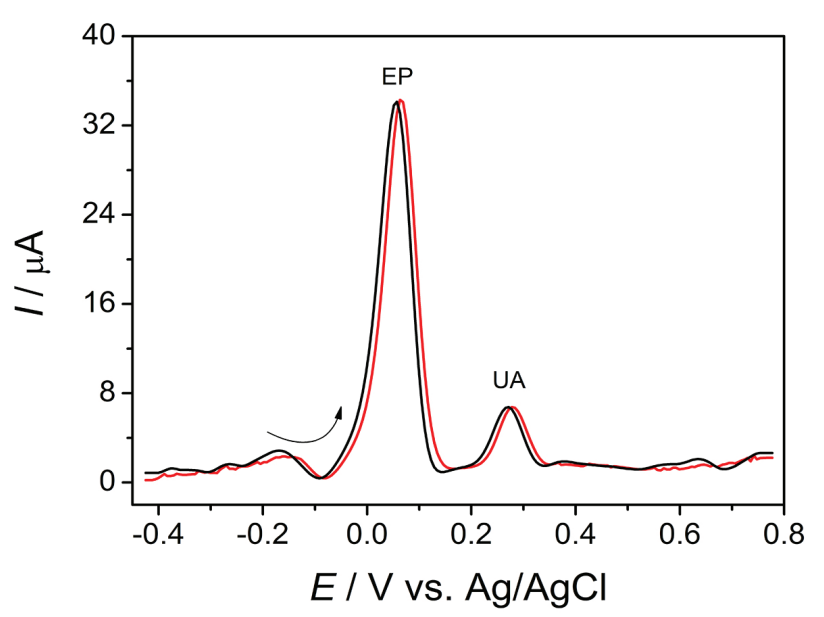

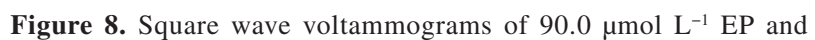
$3.50 \mu \mathrm{mol} \mathrm{L}-1$ UA in absence (black line) and presence (red line) of $50.0 \mathrm{mmol} \mathrm{L}^{-1}$ foreign compounds recorded with $\left[\mathrm{Cu}\left(\mathrm{H}_{2} \operatorname{dimpy}\right) \mathrm{Cl}\right] \mathrm{PF}_{6} /$ MWCNTs/GCE in $0.10 \mathrm{~mol} \mathrm{~L}^{-1} \mathrm{PBS}(\mathrm{pH}=7.0)$. $\mathrm{a}=60 \mathrm{mV}, \mathrm{f}=60 \mathrm{~s}^{-1}$ and $\Delta \mathrm{E}_{\mathrm{s}}=6 \mathrm{mV}$.

did not interfere significantly on the sensor response, meaning that the proposed sensor exhibits good selectivity for the real-time analytical determination of EP and UA.

\section{Real sample analysis and recovery test}

In the analysis of real samples five human urine samples were collected from voluntaries and were diluted to 25 times with $0.10 \mathrm{~mol} \mathrm{~L}^{-1} \mathrm{PBS}$ ( $\mathrm{pH}=7.0$ ) for electrochemical determinations. Furthermore, EP and UA standard solutions with varying concentrations were added to the urine samples to recovery tests in triplicate and the peak currents were measured by SWV using the $\left[\mathrm{Cu}\left(\mathrm{H}_{2}\right.\right.$ dimpy)Cl] $\mathrm{PF}_{6} / \mathrm{MWCNTs} / \mathrm{GCE}$ (Table 3). The percentage recovery values were determined from the difference between the concentration obtained in the human urine samples and the nominal concentrations. The EP recovery percentage in the spiked samples ranged between 96.0 and $104 \%$, while the UA recovery percentage ranged between 96.7 and $105 \%$, respectively, resulting in an excellent accuracy ${ }^{49}$ These results indicate that this $\left[\mathrm{Cu}\left(\mathrm{H}_{2}\right.\right.$ dimpy)Cl $] \mathrm{PF}_{6} / \mathrm{MWCNTs} / \mathrm{GCE}$ could be an efficient tool for the determination of EP and UA in real samples.

\section{Conclusions}

This work showed that $\left[\mathrm{Cu}\left(\mathrm{H}_{2}\right.\right.$ dimpy $\left.) \mathrm{Cl}\right] \mathrm{PF}_{6} / \mathrm{MWCNTs} /$ GCE is a feasible alternative for the simultaneous determination of EP and UA by SWV. The modified electrode exhibited excellent responses towards EP and UA quantifications due to the low resistance to charge transfer and electrocatalytic effect. Optimization of the experimental conditions yielded high sensitivity and low limits of detection, which were comparable with previous works dedicated to the simultaneous analysis of EP and UA by electrochemical methods. Furthermore, the developed method provides results with adequate intra-day and interday repeatability. Additional advantages such as simplicity, fast preparation and low costs were also obtained. The study of the mechanism of the electrochemical activation 
Table 3. Results of epinephrine (EP) and uric acid (UA) addition-recovery experiments with urine samples using the $\mathrm{SWV}-\left[\mathrm{Cu}\left(\mathrm{H}_{2} \mathrm{dimpy}\right) \mathrm{Cl}\right] \mathrm{PF} / \mathrm{MWCNTs} /$ GCE method

\begin{tabular}{|c|c|c|c|c|c|c|c|c|}
\hline $\begin{array}{l}\text { Human urine } \\
\text { sample }\end{array}$ & $\begin{array}{c}{[\mathrm{EP}] \text { added }} \\
(\mathrm{n}=3) / \\
(\mu \mathrm{mol} \mathrm{L}-1) \\
\end{array}$ & $\begin{array}{c}{[\mathrm{EP}] \text { expected }} \\
(\mathrm{n}=3) / \\
\left(\mu \mathrm{mol} \mathrm{L}{ }^{-1}\right)\end{array}$ & $\begin{array}{c}{[\mathrm{EP}] \text { found }} \\
(\mathrm{n}=3) / \\
\left.(\mu \mathrm{mol} \mathrm{L})^{-1}\right)\end{array}$ & Recovery / \% & $\begin{array}{c}{[\mathrm{UA}] \text { added }} \\
(\mathrm{n}=3) / \\
\left(\mu \mathrm{mol} \mathrm{L}{ }^{-1}\right)\end{array}$ & $\begin{array}{c}{[\mathrm{UA}] \text { expected }} \\
(\mathrm{n}=3) / \\
\left.(\mu \mathrm{mol} \mathrm{L})^{-1}\right)\end{array}$ & $\begin{array}{c}{[\mathrm{UA}] \text { found }} \\
(\mathrm{n}=3) / \\
(\mu \mathrm{mol} \mathrm{L}-1)\end{array}$ & Recovery / \% \\
\hline \multirow{4}{*}{ A } & 0.00 & - & 0.00 & - & 0.00 & - & $0.18 \pm 0.02$ & - \\
\hline & 0.25 & 0.25 & $0.24 \pm 0.03$ & $96.0 \pm 0.2$ & 0.50 & 0.68 & $0.71 \pm 0.03$ & $104 \pm 0.2$ \\
\hline & 0.50 & 0.50 & $0.49 \pm 0.02$ & $98.0 \pm 0.1$ & 1.00 & 1.18 & $1.23 \pm 0.05$ & $104 \pm 0.4$ \\
\hline & 1.00 & 1.00 & $1.01 \pm 0.03$ & $101 \pm 0.2$ & 5.00 & 5.18 & $5.12 \pm 0.04$ & $98.8 \pm 0.3$ \\
\hline \multirow{4}{*}{ B } & 0.00 & - & 0.00 & - & 0.00 & - & $1.10 \pm 0.08$ & - \\
\hline & 0.25 & 0.25 & $0.24 \pm 0.02$ & $96.0 \pm 0.1$ & 0.50 & 1.60 & $1.68 \pm 0.07$ & $105 \pm 0.6$ \\
\hline & 0.50 & 0.50 & $0.50 \pm 0.01$ & $102 \pm 0.1$ & 1.00 & 2.10 & $2.07 \pm 0.03$ & $98.6 \pm 0.2$ \\
\hline & 1.00 & 1.00 & $0.98 \pm 0.04$ & $98.0 \pm 0.4$ & 5.00 & 6.10 & $6.05 \pm 0.05$ & $99.2 \pm 0.4$ \\
\hline \multirow{4}{*}{$\mathrm{C}$} & 0.00 & - & 0.00 & - & 0.00 & - & $0.48 \pm 0.05$ & - \\
\hline & 0.25 & 0.25 & $0.25 \pm 0.02$ & $100 \pm 0.3$ & 0.50 & 0.98 & $1.01 \pm 0.03$ & $103 \pm 0.2$ \\
\hline & 0.50 & 0.50 & $0.52 \pm 0.01$ & $104 \pm 0.2$ & 1.00 & 1.48 & $1.51 \pm 0.01$ & $102 \pm 0.1$ \\
\hline & 1.00 & 1.00 & $1.02 \pm 0.04$ & $102 \pm 0.5$ & 5.00 & 5.48 & $5.53 \pm 0.06$ & $101 \pm 0.5$ \\
\hline \multirow{4}{*}{ D } & 0.00 & - & 0.00 & - & 0.00 & - & $3.60 \pm 0.04$ & - \\
\hline & 0.25 & 0.25 & $0.26 \pm 0.05$ & $104 \pm 0.6$ & 0.50 & 4.10 & $4.09 \pm 0.02$ & $99.8 \pm 0.1$ \\
\hline & 0.50 & 0.50 & $0.48 \pm 0.06$ & $96.0 \pm 0.4$ & 1.00 & 4.60 & $4.68 \pm 0.06$ & $102 \pm 0.4$ \\
\hline & 1.00 & 1.00 & $0.97 \pm 0.07$ & $97.0 \pm 0.6$ & 5.00 & 8.60 & $8.43 \pm 0.08$ & $98.0 \pm 0.6$ \\
\hline \multirow{4}{*}{$\mathrm{E}$} & 0.00 & - & 0.00 & - & 0.00 & - & $0.11 \pm 0.06$ & - \\
\hline & 0.25 & 0.25 & $0.26 \pm 0.02$ & $104 \pm 0.1$ & 0.50 & 0.61 & $0.59 \pm 0.02$ & $96.7 \pm 0.1$ \\
\hline & 0.50 & 0.50 & $0.52 \pm 0.01$ & $104 \pm 0.2$ & 1.00 & 1.11 & $1.08 \pm 0.04$ & $97.3 \pm 0.3$ \\
\hline & 1.00 & 1.00 & $1.03 \pm 0.02$ & $103 \pm 0.4$ & 5.00 & 5.11 & $5.05 \pm 0.01$ & $98.8 \pm 0.1$ \\
\hline
\end{tabular}

revealed that a synergistic effect is responsible for the enhanced activity. The $\left[\mathrm{Cu}\left(\mathrm{H}_{2} \text { dimpy }\right) \mathrm{Cl}\right]^{+}$complex interacts with CNT walls through $\pi$-stacking and also acts as an hydrogen-bond donor for both epinephrine and uric acid.

\section{Supplementary Information}

Supplementary information is available free of charge at http://jbcs.sbq.org.br as PDF file and it contains detailed descriptions of used chemicals and apparatus, theoretical calculations and extra information on the electrochemical characterization of the modified electrodes.

\section{Acknowledgments}

The authors thank the Financiadora de Inovação e Pesquisa (FINEP, Brazil) (agreement number: 01.12.0208.00), Conselho Nacional de Desenvolvimento Científico e Tecnológico (CNPq, Brazil, grants No. 131848/2013-5, No. 465452/2014-0), Coordenação de Aperfeiçoamento de Pessoal de Nível Superior (CAPES, Brazil, finance code 001), Fundação de Amparo à Pesquisa do Estado de São Paulo (FAPESP, Brazil, grants No. 2013/22127-2, No. 2014-50906-9 and No. 2018-03576-4), National Institute of Science and Technology in Complex Functional Materials (CNPq-MCT/FAPESP), Fundação de Amparo à Pesquisa do Estado de Minas Gerais (FAPEMIG, Brazil) for the financial support. The authors also thank the support from LMMA Laboratory sponsored by FAPEMIG, Brazil (project: CEX-112-10), Secretaria de Estado de Ciência, Tecnologia e Ensino Superior do Estado de Minas Gerais (SECTES/MG, Brazil) and Rede Mineira de Química (RQ-MG) supported by FAPEMIG, Brazil (project: CEX - RED-00010-14).

\section{Author Contributions}

Bruno R. L. Ferraz, Fernando R. F. Leite, Eliziana S. Gomes, and Marcus L. Sousa contributed with investigation, formal analysis and writing (original draft, review and editing); Eduardo G. R. de Arruda contributed with investigation; Juliano A. Bonacin contributed with conceptualization, project administration, resources and writing (review and editing); Andréa R. Malagutti and André L. B. Formiga contributed with conceptualization, project administration, resources, investigation, formal analysis, methodology, supervision and writing (original draft, review and editing).

\section{References}

1. Lehn, J.-M.; Angew. Chem., Int. Ed. Engl. 1990, 29, 1304.

2. Toma, H. E.; Araki, K.; Coord. Chem. Rev. 2000, 196, 307. 
3. Balzani, V.; Credi, A.; Venturi, M.; Molecular Devices and Machines: Concepts and Perspectives for the Nanoworld, $2^{\text {nd }}$ ed.; John Wiley \& Sons: Weinheim, 2008.

4. Jannuzzi, S. A. V.; de Arruda, E. G. R.; Lima, F. A.; Ribeiro, M. A.; Brinatti, C.; Formiga, A. L. B.; ChemistrySelect 2016, $1,2235$.

5. Gallo, M. C.; Pires, B. M.; Toledo, K. C. F.; Jannuzzi, S. A. V.; Arruda, E. G. R.; Formiga, A. L. B.; Bonacin, J. A.; Synth. Met. 2014, 198, 335.

6. Jannuzzi, S. A. V.; Martins, B.; Felisberti, M. I.; Formiga, A. L. B.; J. Phys. Chem. B 2012, 116, 14933.

7. Jannuzzi, S. A. V.; Martins, B.; Huamaní, L. E. S. C.; Formiga, A. L. B.; J. Braz. Chem. Soc. 2017, 28, 2.

8. Corrêa, C. C.; Jannuzzi, S. A. V.; Santhiago, M.; Timm, R. A.; Formiga, A. L. B.; Kubota, L. T.; Electrochim. Acta 2013, 113, 332.

9. de Arruda, E. G. R.; de Farias, M. A.; Jannuzzi, S. A. V.; Gonsales, S. A.; Timm, R. A.; Sharma, S.; Zoppellaro, G.; Kubota, L. T.; Knobel, M.; Formiga, A. L. B.; Inorg. Chim. Acta 2017, 466, 456.

10. Guerra, R. B.; Huamaní, L. S. C.; Tenorio, J. C.; Guimarães, W. M.; Bonacin, J. A.; Formiga, A. L. B.; Acta Crystallogr., Sect. C: Cryst. Struct. Commun. 2019, 75, 1359.

11. Huamaní, L. E. S. C.; Tenorio, J. C.; Guerra, R. B.; Nakahata, D. H.; Bibi, N.; Bonacin, J. A.; Formiga, A. L. B.; Cryst. Growth Des. 2020, 20, 5143.

12. dos Santos, P. L.; Timm, R. A.; Kubota, L. T.; Bonacin, J. A.; ChemistrySelect 2016, 1, 1168.

13. dos Santos, P. L.; Katic, V.; Loureiro, H. C.; dos Santos, M. F.; dos Santos, D. P.; Formiga, A. L. B.; Bonacin, J. A.; Sens. Actuators, B 2019, 281, 837.

14. Iijima, S.; Nature 1991, 354, 56.

15. Jiang, H.-J.; Zhao, Y.; Yang, H.; Akins, D. L.; Mater. Chem. Phys. 2009, 114, 879.

16. Mao, A.; Li, H.; Jin, D.; Yu, L.; Hu, X.; Talanta 2015, 144, 252.

17. Leite, F. R. F.; Maroneze, C. M.; de Oliveira, A. B.; dos Santos, W. T. P.; Damos, F. S.; Luz, R. C. S.; Bioelectrochemistry 2012, $86,22$.

18. de Holanda, L. F.; Ribeiro, F. W. P.; Sousa, C. P.; Casciano, P. N. S.; de Lima-Neto, P.; Correia, A. N.; J. Electroanal. Chem. 2016, 772, 9.

19. Li, Y.; Umasankar, Y.; Chen, S.-M.; Anal. Biochem. 2009, 388, 288.

20. El Bouhouti, H.; Naranjo-Rodríguez, I.; de Cisneros, J. L. H.-H.; ElKaoutit, M.; Temsamani, K. R.; Bouchta, D.; Cubillana Aguilera, L. M.; Talanta 2009, 79, 22.

21. Huo, J.; Shangguan, E.; Li, Q.; Electrochim. Acta 2013, 89, 600.

22. Revin, S. B.; John, S. A.; Bioelectrochemistry 2012, 88, 22.

23. Grabowska, I.; Chudy, M.; Dybko, A.; Brzozka, Z.; Sens. Actuators, B 2008, 130, 508.

24. Zare, H. R.; Nasirizadeh, N.; Sens. Actuators, B 2010, 143, 666.
25. Ensafi, A. A.; Rezaei, B.; Zare, S. Z. M.; Taei, M.; Sens. Actuators, B 2010, 150, 321.

26. Shahrokhian, S.; Khafaji, M.; Electrochim. Acta 2010, 55, 9090.

27. Tsai, T.-H.; Thiagarajan, S.; Chen, S.-M.; Cheng, C.-Y.; Thin Solid Films 2012, 520, 3054.

28. Justino, D. D.; Lage, A. L. A.; Souto, D. E. P.; da Silva, J. V.; dos Santos, W. T. P.; Luz, R. C. S.; Damos, F. S.; J. Electroanal. Chem. 2013, 703, 158.

29. Dorraji, P. S.; Jalali, F.; Sens. Actuators, B 2014, 200, 251.

30. Lavanya, N.; Fazio, E.; Neri, F.; Bonavita, A.; Leonardi, S. G.; Neri, G.; Sekar, C.; Sens. Actuators, B 2015, 221, 1412.

31. Voss, M. E.; Beer, C. M.; Mitchell, S. A.; Blomgren, P. A.; Zhichkin, P. E.; Tetrahedron 2008, 64, 645.

32. Stupka, G.; Gremaud, L.; Bernardinelli, G.; Williams, A. F.; Dalton Trans. 2004, 407.

33. NOVA software, version 1.10.4; Metrohm Autolab BV, Kanaalweg 29/G, 3526 KM, Utrecht, The Netherlands, 2014.

34. Ferraz, B. R. L.; Leite, F. R. F.; Malagutti, A. R.; Talanta 2016, 154, 197.

35. Rappe, A. K.; Casewit, C. J.; Colwell, K. S.; Goddard, W. A.; Skiff, W. M.; J. Am. Chem. Soc. 1992, 114, 10024.

36. Řezáč, J.; Hobza, P.; J. Chem. Theory Comput. 2012, 8, 141.

37. Stewart, J. J. P.; MOPAC 2016, version 19.338L; Stewart Computational Chemistry, Colorado Springs, CO, USA, 2016. Available at http://OpenMOPAC.net, accessed in July 2020.

38. Hunter, C. A.; Sanders, J. K. M.; J. Am. Chem. Soc. 1990, 112, 5525.

39. Gosser, D. K.; Cyclic Voltammetry: Simulation and Analysis of Reaction Mechanisms, vol. 43; VCH: New York, 1993.

40. Bard, A. J.; Faulkner, L. R.; Electrochemical Methods: Fundamentals and Applications; John Wiley \& Sons, Inc.: New York, 2000.

41. Corona-Avendaño, S.; Alarcón-Angeles, G.; Rojas-Hernández, A.; Romero-Romo, M. A.; Ramírez-Silva, M. T.; Spectrochim. Acta, Part A 2005, 61, 305.

42. Simic, M. G.; Jovanovic, S. V.; J. Am. Chem. Soc. 1989, 111, 5778.

43. Analytical Methods Committee; Analyst 1987, 112, 199.

44. Chen, M. F.; Ma, X. Y.; Russ. J. Appl. Chem. 2014, 87, 200.

45. Koçak, Ç. C.; Dursun, Z.; J. Electroanal. Chem. 2013, 694, 94.

46. Beitollahi, H.; Ardakani, M. M.; Ganjipour, B.; Naeimi, H.; Biosens. Bioelectron. 2008, 24, 362.

47. Qiao, J. X.; Luo, H. Q.; Li, N. B.; Colloids Surf., B 2008, 62, 31.

48. Mazloum-Ardakani, M.; Beitollahi, H.; Amini, M. K.; Mirjalili, B.-F.; Mirkhalaf, F.; J. Electroanal. Chem. 2011, 651, 243.

49. Thompson, M.; Ellison, S. L.; Fajgelj, A.; Willetts, P.; Wood, R.; Pure Appl. Chem. 1999, 71, 337.

Submitted: June 23, 2020

Published online: July 30, 2020 